\title{
CONSIDERAÇÕES SOBRE O CONCEITO DE DESIGN NO CONTEXTO DO PÓS- INDUSTRIALISMO E DA CULTURA PÓS-MODERNA
}

\author{
CARVALHO, Alecir Francisco de \\ PUC-RIO / UEMG \\ alecircarvalho@gmail.com
}

\begin{abstract}
Resumo: As diversas transformações culturais, sociais e tecnológicas que impactaram o design na contemporaneidade necessitam ser compreendidas como fenômenos que gradativamente foram estabelecidos na sociedade, modificando ao longo dos anos diversas áreas do conhecimento. $\mathrm{O}$ design, como uma atividade multidisciplinar, protagoniza um rearranjo, sendo necessário refletir sobre suas práticas, suas estratégias, bem como sobre o seu papel nesta sociedade, na qual predominam as consequências de uma cultura pós-industrial e pósmoderna. E para se compreender o campo e a condição do design na atualidade, é necessário, além de revisitar sua trajetória histórica, analisar seu contexto atual, no qual as relações sociais estão cada vez mais dinâmicas, complexas e mutantes. Dessa forma, o presente artigo propõe fazer uma reflexão crítica sobre o percurso histórico do design, tecendo uma análise sobre as formulações em seu conceito e considerando fatores e fenômenos que o influenciaram na contemporaneidade.
\end{abstract}

Palavras-chave: Conceito de Design, Pós-Industrialismo, Cultura Pósmoderna.

\begin{abstract}
The various cultural, social and technological changes that impacted the contemporary design need to be understood as phenomena that were gradually established in society changed over the years various areas of knowledge. The design as a multidisciplinary activity which carries a rearrangement is necessary to reflect on their practices, their strategies and their role in this society dominated the consequences of a postindustrial and post-modern culture. And to understand the design and condition of the field today, it is necessary in addition to revisit its historical trajectory, analyze your current context where social relationships are increasingly dynamic, complex and mutant. This paper proposes a critical reflection on the historical background of weaving a design analysis of the formulations in its concept, considering factors and phenomena that influenced the contemporary.
\end{abstract}

Keywords: Concept Design, Post-industrialism, Post-Modern Culture. 


\section{INTRODUÇÃO}

Para compreensão das bases epistemológicas do design no cenário pósmoderno e entendimento preliminar dos fundamentos históricos deste campo, tornase necessário considerar os conceitos característicos essenciais de referido período, assim como promover revisita às diversas concepções que sustentam o conceito de design. Para tanto, é possível introduzir uma discussão por meio de uma breve abordagem dos fenômenos sociais, culturais e políticos do período contemporâneo, assim como realizar uma análise crítica no âmbito da trajetória do design em seu contexto histórico. Neste sentido, também se faz necessário realizar um diagnóstico do conceito multifacetado do design e suas implicações, aplicações e repercussões no atual cenário complexo e dinâmico. Assim, será possível promover uma análise de seu percurso histórico a partir de suas formulações constitutivas numa tentativa de compreensão do universo do design na contemporaneidade, relacionando-o diretamente com os diversos fenômenos que compõem a chamada cultura pósmoderna.

A contemporaneidade pode ser caracterizada como um período marcado por profundas mudanças econômicas, sociais, políticas culturais que evidenciam as transformações na relação espaço e tempo, gerando repercussões nos modos de compreender novos cenários, marcados pela presença de incertezas e desconectados da causalidade e previsibilidade de momentos anteriores. Tais acontecimentos, associados aos novos modos de organização socioeconômica, a partir da globalização, tendem a impactar incisivamente nas práticas projetuais e no contexto da atuação do design.

Um novo contexto que se estabelece atualmente pode ser caracterizado como dinâmico, no qual predomina a rapidez de transformações na sociedade, gerando novos hábitos e posturas num estado dinâmico e fluído. Para Bauman (1999, p. 20) as coisas "mudam demasiadamente depressa para que as habilidades da purificação se deem conta disso, (o que) já não parece seguro: a incerteza e a desconfiança governam a época".

No período atual, tem sido possível presenciar várias transformações na esfera econômica, cultural, tecnológica, social e política que contribuem para a promoção de uma caracterização de um espaço compreendido a partir da dinâmica da descontinuidade, da complexidade, através do ritmo acelerado de tais mudanças. A partir disso, nota-se um modelo de globalização com mutações fortalecidas pela lógica do progresso e pelo surgimento de novas tecnologias de comunicação e produção que caracterizam a cultura pós-moderna. Assim, também se observa uma dinâmica que impulsiona as mudanças que estabelecem impacto nas relações da divisão internacional do trabalho e também nas relações contemporâneas de produção e consumo no âmbito do design.

Alguns estudiosos sustentam a afirmação de que a sociedade atual vivencia um período caracterizado pelo estabelecimento de fenômenos dinâmicos com características velozes, atingindo diversas dimensões sociais. Dessa forma, surgem diversas formulações que buscam o entendimento dessas características, nas quais prevalecem a complexidade, a dinamicidade, a fluidez e a descontinuidade, na tentativa de compreender o cenário contemporâneo. 
Conforme afirma Anthony Giddens,

[...] muita gente argumenta que estamos no limiar de uma nova era, a qual as ciências sociais devem responder e que está nos levando para além da própria modernidade. Uma estonteante variedade de termos tem sido sugerida para esta transição, alguns dos quais se referem positivamente à emergência de um novo tipo de sistema social (tal como a "sociedade de informação" ou a "sociedade de consumo"). Mas cuja maioria sugere que, mais que um estado de coisas precedente, está chegando a um encerramento ("pós-modernidade", "pós-modernismo", "sociedade pósindustrial", e assim por diante). Alguns dos debates sobre estas questões se concentram principalmente sobre transformações institucionais, particularmente as que sugerem que estamos nos deslocando de um sistema baseado na manufatura de bens materiais para outro relacionado mais centralmente com informação. (GIDDENS, 1991, p.08).

Tais modificações na sociedade contemporânea acabam por influenciar algumas formulações de outros estudiosos numa tentativa de aproximação do entendimento das dinâmicas atuais.

Bauman opta por reconhecer o cenário como "leve e líquido":

Sabemos pela prática que quanto mais leves viajamos, com maior facilidade e rapidez nos movemos. Essas são razões para considerar "fluidez" ou "liquidez" como metáforas adequadas quando queremos captar a natureza da presente fase, nova de muitas maneiras, na história da modernidade. Concordo prontamente que tal proposição deve fazer vacilar quem transita à vontade no "discurso da modernidade" e está familiarizado com o vocabulário usado normalmente para narrar a história moderna. Mas a modernidade não foi um processo de "liquefação" desde o começo? Não foi o "derretimento dos sólidos", seu maior passatempo e principal realização? Em outras palavras, a modernidade não foi "fluida" desde sua concepção? (BAUMAN, 2000, p. 08-09).

O design, por sua vez, teve ao longo dos anos uma trajetória marcada por influências de diferentes concepções que contribuíram para a constituição de seu conceito. Além disso, recebeu interferências de fenômenos socioculturais em contextos históricos diferentes que acabaram por caracterizar significativamente sua definição. Algumas dessas formulações o relacionam apenas às atividades de concepção de objetos a serem fabricados em série pela indústria. Ainda que esse entendimento se aplique em suas práticas e que esse conceito tenha permanecido por um longo período, considera-se essa definição incompleta para sua totalidade, bem como carregada de algumas imprecisões. É percebida, por exemplo, uma ambiguidade nesse conceito por este não distinguir explicitamente as funções no âmbito da engenharia das atuações do profissional designer. Para Maldonado (1999, p. 11), referido conceito de design "não diz onde começa nem onde acaba o papel projectivo de um e de outro, no desenvolvimento de um produto fabricado industrialmente".

Neste sentido, algumas imprecisões foram geradas pela ausência de uma distinção específica entre o campo do design e da engenharia. Nota-se, por exemplo, uma lacuna no esclarecimento das condições e dos momentos nos quais um 
engenheiro pode ou não eventualmente realizar as atividades de design. Também se percebe que essa concepção considera implicitamente que todos os artefatos não fabricados pela indústria não estão na esfera do design industrial. Percebe-se, neste propósito, a tentativa de esclarecer e evitar equívocos entre design industrial e artesanato, assim como também prevenir imprecisão entre design e arte aplicada. É necessário, assim, distinguir que tais áreas tiveram uma influência decisiva no surgimento da atividade e durante a fase inicial da história do design industrial.

Diferenciar design e arte tem seus aspectos significativos e constitui uma necessidade na caracterização do conceito de design. Além disso, caracteriza-se como um marco na passagem de um tipo de fabricação em que o mesmo indivíduo concebe e executa o artefato para outro em que existe uma separação nítida entre o ato de projetar e de fabricar. Para Cardoso (2004, p. 15) "a diferença entre design e artesanato reside justamente no fato de que o designer se limita a projetar o objeto para ser fabricado por outras mãos ou, de preferência, por meios mecânicos". E, assim, o artesanato assume em geral a participação de apenas um indivíduo no ato de produzir.

Entretanto, não é seguro afirmar que o artesanato seja uma ação realizada exclusivamente por uma pessoa, pois também se considera que a divisão de tarefas teve seu início em manufaturas artesanais. O artesanato também necessita ser compreendido como um processo complexo no qual o maquinário e as ferramentas também atuam como uma extensão das potencialidades físicas e técnicas dos habilidosos artífices.

Todavia, as contribuições de Schneider (2010) asseveram que o processo de mecanização pode ser caracterizado como um fenômeno que além de impulsionar a origem do design também contribuiu para o surgimento da divisão do trabalho.

Nos dizeres de Beat Schneider,

\begin{abstract}
A industrialização mecanizou muitas das atividades que até então eram realizadas manualmente. A mecanização foi acompanhada por uma radical divisão do trabalho, pois nos produtos fabricados industrialmente a unidade artesanal entre projeto e execução ficou cada vez mais cindida. A criação dos objetos (trabalho mental) e a sua produção (trabalho das máquinas) tornaram-se atividades distintas. Aqui, na divisão industrial do trabalho, surgiu a moderna atividade de projeto de produtos, surgiu o design industrial. (SCHNEIDER, 2010, p. 16).
\end{abstract}

Dessa forma, considera-se que o sentido atual do conceito de design industrial surgiu a partir da divisão do trabalho na metade do século XIX, na qual se inicia de fato uma separação entre projeto e manufatura, o que até então era feito pela mesma pessoa. Conforme Bürdek (2006, p. 19), "ele começa com o fato de que a divisão de trabalho separa o projeto da manufatura, o que até ali era feito pela mesma pessoa". Essa especialização se constituiu intensamente ao longo dos anos. Atualmente, designers e grandes fabricantes passaram a ser responsáveis apenas por parte de um produto. 
Segundo Rafael Cardoso,

\begin{abstract}
A maioria das definições concorda que o design opera a junção desses dois níveis, atribuindo forma material a conceitos intelectuais. Trata-se, portanto de uma atividade que gera projetos, no sentido objetivo de planos, esboços ou modelos. Diferentemente de outras atividades ditas projetuais, como a arquitetura e a engenharia, o design costuma projetar determinados tipos de artefatos móveis, se bem que as três atividades sejam limítrofes e se misturem às vezes na prática. A distinção entre design e outras atividades que geram artefatos móveis, como artesanato, artes plásticas e artes gráficas, tem sido outra preocupação constante para os forjadores de definições, e o anseio de alguns designers de se distanciarem do fazer artesanal ou artístico tem engendrado prescrições extremamente rígidas e preconceituosas. (CARDOSO, 2004, p. 14).
\end{abstract}

Muitos estudiosos afirmam que o conceito de design possui, dentre outros, o significado de atender à necessidade de dar forma a produtos industriais, imprimindo valores culturais e valores de uso, criando estratégias para satisfazer a demanda de clientes e usuários. Para esses, o design assume também o papel de contribuir para a vida social e individual, priorizando o enfoque em aspectos práticos de uso, de comunicação e de percepção, considerando questões sociais, econômicas e ambientais.

Numa avaliação das diversas contribuições para a definição do conceito de design, é possível observar que o design não se apresenta apenas na produção seriada de artefatos industriais, uma vez que precisa ser compreendido também como um processo multidisciplinar de projetar produtos e serviços. Entende-se o design como uma atividade que vem se adequando aos vários cenários que surgem em diferentes épocas. Logo, torna-se necessário perceber o design como uma prática capaz de corresponder à diversidade, às possibilidades de construção de valores, ao multiculturalismo e à própria dinamicidade presentes na sociedade.

\title{
2. O PERCURSO DO DESIGN E SUAS INFLUÊNCIAS
}

Os diversos debates que se estabelecem acerca da definição de design acabam se direcionando para precisar o momento histórico em que se concretiza a transição do processo de fabricação por uma pessoa para outro período no qual a tarefa a ser realizada envolve mais de um indivíduo. Surgem também, nesse momento, esforços para retratar o momento da inserção de meios mecânicos incorporados no processo produtivo, distinguindo, assim, a atividade de projetar e conceber objetos destinados a profissionais específicos.

O exato momento de inserção de meios mecânicos no processo produtivo é controverso; porém, é possível destacar alguns acontecimentos, como o advento da imprensa no século XV. Para Cardoso (2004, p. 17), "os exemplos se multiplicam a partir da fabricação mecanizada de peças para relógios no final do século XVII, e o século XVIII testemunhou a introdução de um alto grau de divisão do trabalho [...]".

Já que não é simples precisar o início da separação entre projeto e execução, é possível ao menos reconhecer a época em que o termo designer passou a ser utilizado 
como distinção profissional. No início do século XIX é que surge especificamente na Inglaterra um número considerável de trabalhadores que já se intitulavam designers, ligados principalmente à indústria têxtil. Essa época corresponde à generalização da divisão intensiva de trabalho, que é uma das características mais importantes da primeira Revolução Industrial. Dessa forma, não resta dúvida de que a existência de atividades ligadas ao design antecede a aparição da figura do designer.

É possível considerar que os primeiros designers surgiram nas fábricas dentro do processo de produção, permanecendo desconhecidos: eram profissionais que, no surgimento das primeiras indústrias, possuíam a habilidade de concepção e planejamento de projetos em comparação às outras fases da divisão do trabalho. Tempos depois, iniciou-se o entendimento do significado da atividade no processo de produção, fazendo emergir a necessidade de sistematização das práticas e o surgimento dos possíveis impactos nos modos de fazer, pensar e compreender o design, tanto como uma atividade para indústrias específicas quanto para o exercício em diversos projetos.

Para Rafael Cardoso, designers

\begin{abstract}
[...] eram aqueles operários promovidos por quesitos de experiência ou habilidade a uma posição de controle e concepção, em relação às outras etapas da divisão de trabalho. A transformação dessa figura de origens operárias em um profissional liberal, divorciado da experiência produtiva de uma indústria específica e habilitado a gerar projetos de maneira genérica, corresponde a um longo processo evolutivo que teve seu início na organização das primeiras escolas de design do século XIX e que continuou com a institucionalização do campo ao longo do século XX". (CARDOSO, 2004, p. 16).
\end{abstract}

Gradativamente, a atividade de design foi sendo considerada uma prática que correspondesse e implicasse em melhorias na produção e no consumo. Aos poucos, acabou se tornando uma área que precisava ser pesquisada e analisada por aqueles que estivessem envolvidos em seu campo. Surgiram iniciativas que propunham esforços para uma análise e estruturação de metodologias a fim de possibilitar melhor entendimento de seu âmbito. Citam-se nessa perspectiva o surgimento das escolas Bauhaus e escola de Ulm, na Alemanha, como instituições que se destacaram ao longo da trajetória do design, com pesquisas, metodologias e análise sistematizadas.

Estabelecida em 1919, na cidade de Weimar, na Alemanha, a Escola Staatliches Bauhaus (mais conhecida simplesmente por Bauhaus) nasceu da fusão de dois institutos de ensino preexistentes: a Grossherzogliche Hochschule für bildende Kunst (Escola Superior de Belas Artes) e a Grossherzogliche Kunstgewerbeschule (Escola de Arte Aplicada) ${ }^{1}$. Os integrantes da escola, percebendo que aquele momento se caracterizava pelo início de um novo período com o fim da primeira guerra mundial, decidiram criar um conceito que refletisse os aspectos daquela época: criação de bens de consumo que primavam pela funcionalidade, com redução de custo e orientação para a produção em massa.

\footnotetext{
${ }^{1}$ MALDONADO, Tomás. Design Industrial. Lisboa/Portugal: Edições 70, 1999. p. 51.
} 
A Escola Bauhaus foi uma das primeiras escolas de design no mundo, caracterizada pela sua marcante expressão do chamado modernismo no design e na arquitetura. Além de uma prática do racionalismo funcional, a instituição buscava perceber suas limitações para permitir ao processo criativo a construção de algo novo a partir da base tecnológica da época. Um dos objetivos da Escola Bauhaus era o de repensar um novo conceito de design que fosse acessível a todas as faixas sociais alemãs, abandonando os princípios burgueses e empregando o expressionismo como linguagem.

A Bauhaus procurou inserir em todas as suas produções um formato simples e limpo, utilizando formas geométricas e o uso de cores básicas, em geral o preto e o branco, para contrastar com as cores fortes utilizadas pela burguesia naquele período. Com seu estilo limpo e simples em seus projetos, a escola, além de influenciar diversos designers, dentro e fora da Alemanha, também se esforçou em influenciar a tipografia, afirmando que as fontes poderiam possuir formas menos complexas, assumindo certa simplicidade e dispensando o uso de letras maiúsculas. Essa proposta se adequava aos ideais de seu movimento, uma vez que facilitaria para as camadas sociais a leitura e o acesso à informação.

Através de sua forte posição contrária aos conservadores da época, a escola Bauhaus começou a se sentir politicamente ameaçada de dissolução e se transferiu em 1925. Conforme Bürdek,

\footnotetext{
a sede da Bauhaus era, a partir de 1919, Weimar. Em 1925, mudou-se para o novo prédio em Dessau, projetado por Gropius, no qual trabalhou durante sete anos. Sob pressão dos Nacional - Socialistas (Nazistas), a Bauhaus em Dessau foi fechada, mas um pequeno grupo de professores e de alunos continuou ativo, mesmo que com muita dificuldade em Berlim, durante os anos de 1932 e 1933. Tratava-se de uma iniciativa privada de Mies van der rohe que fechou as portas definitivamente no verão de 1933. (BÜRDEK, 2006, p. 29)
}

Ainda que não se tenha muitos relatos sobre as consequências implícitas do nazismo nesta fase de desenvolvimento do design, certamente pode se considerar que foi um fato que gerou implicações muito além do simples deslocamento da Bauhaus de uma região para outra. A Escola Bauhaus pode ser considerada como peça-chave do movimento que gerou o design moderno, um verdadeiro marco na história do design, revolucionando escolas e sendo exemplo em todo o mundo. Um desses exemplos, que pode ser citado, está em seu papel social desempenhado historicamente e nos métodos de ensino que serviram para o surgimento de outras instituições de ensino, como o instituto Hochschule für Gestaltung de Ulm.

Também conhecida como Escola de Ulm, essa instituição apresentava métodos de ensino e objetivos de recuperar a tradição da Bauhaus. A Escola de Ulm foi Inaugurada em 1955. Recebia o nome de Escola Superior da Forma e foi uma proposta significativa de restabelecer a ligação com a tradição do design na Alemanha e de gerar uma concepção moderna própria. Conforme Maldonado (1999, p. 74), "este instituto foi oficialmente inaugurado em 1955, com um discurso de Gropius (fundador da Bauhaus); era seu objetivo retomar a tradição Bauhaus interrompida em 1933 pelo nazismo". Suas instalações foram desenhadas por Max Bill, seu primeiro diretor, que 
encarava a Escola de Ulm como uma academia sucessora da Bauhaus, fosse por seus métodos de ensino, disciplinas lecionadas, ideais políticos ou por também acreditar que o design tinha um importante papel social a cumprir.

A Escola de Ulm formou designers com um vínculo forte com a ciência. Nos seus últimos anos, já perto da dissolução, a escola trabalhou em colaboração com empresas como a Kodak e a Braun. Seguramente os projetos industriais deveriam dar à escola uma forte orientação para a prática, mas as disputas por sua liderança e as influências políticas e tecnológicas acabaram por levar ao seu fechamento.

Assim como na Alemanha, que presenciou um período político conturbado durante a origem do design, com ameaças ao movimento da Bauhaus e o advento do nazismo, é possível reconhecer que o design no Brasil também testemunhou uma época conflituosa com as repercussões do militarismo. É necessário destacar que, desde o início da instituição do design no Brasil, o país não parou de receber influências, métodos, conceitos e teorias provenientes dos centros mais industrializados, determinando, portanto, uma estreita relação entre as referências nacionais e os modelos e conceitos vindos do exterior. Tais influências contribuíram para estabelecer um contínuo fenômeno de confluências ideológicas no design brasileiro.

\section{O DESIGN E O SURGIMENTO DA CULTURA PÓS-MODERNA}

A partir da segunda metade do século $X X$, tem sido possível notar diversas transformações socioculturais e políticas, tais como o surgimento do fenômeno pósindustrialismo, como lembra Bell (1976). O surgimento de novas tecnologias, configurando novas definições e alterações na esfera do trabalho, acabou por repercutir no âmbito de diversos campos, bem como no campo da arte e do design. Tais alterações proporcionaram um impacto de dimensões globais e acabam por ainda refletir e provocar mudanças no contexto atual. E nesse sentido, para traçar um panorama sobre a contemporaneidade, necessário é considerar discussões no âmbito da compreensão dos conceitos sobre a cultura pós-moderna e os debates que se estabelecem para uma compreensão dos tempos modernos e pós-modernos. Assim, torna-se válido promover breves discussões introdutórias sobre a temática a partir de reflexões construídas pelos estudiosos Baumam (2000), Giddens (1991) e Lyotard (2000) com suas respectivas análises de rupturas, consequências e condições sociais no cenário contemporâneo.

O design, por percorrer e acompanhar mudanças ocorridas desde a origem da cultura pós-moderna, acabou por também protagonizar as transformações geradas a partir da década de 1950, bem como sofrer as repercussões gestadas que influenciaram e impactaram em seu papel, conduzindo para formulações de reflexões sobre sua prática. Considera-se que sem as certezas do paradigma da época anterior, o design enfrenta um período de insegurança e de esperanças, caracterizado pelo pluralismo e pela convivência com a complexidade. Nos dizeres de Cardoso (2004, p. 208), "o design vem se libertando da rigidez normativa que dominou o campo durante mais de meio século". 


\title{
4. O DESIGN E AS CONSEQUÊNCIAS DA MODERNIDADE
}

Compreender o papel do design no contexto atual requer também uma análise sobre a verdadeira concepção diagnóstica do que seria o momento vivido atualmente pela sociedade.

Há algumas formulações que caracterizam tal concepção como um momento de perda das incertezas, ausência da estabilidade, originando uma nova época reconhecida como pós-modernidade. Entretanto, há também o surgimento de formulações que se esforçam e percebem este mesmo período como um momento singular, marcado pela dinamicidade e rapidez dos fenômenos globais e constituído por uma sociedade que formula as ideias e os pensamentos que a conceituam com um período que surge a partir de acontecimentos proporcionados pela modernidade, ou seja, vive-se as consequências da modernidade, mas não estritamente uma época pósmoderna. Logo, o que se vivencia é um período posterior à modernidade, mas não a pós-modernidade.

Nos dizeres de Anthony Giddens,

\begin{abstract}
Pós-modernidade é usado frequentemente como se fosse sinônimo de pósmodernismo, sociedade pós-industrial etc. Embora a ideia de sociedade pósindustrial, como desenvolvida por Daniel Bell, pelo menos, seja bem explicada, os outros dois conceitos mencionados acima certamente não o são. (GIDDENS, 1991, p. 45).

Em vez de estarmos entrando num período de pós-modernidade, estamos alcançando um período em que as consequências da modernidade estão se tornando mais radicalizadas e universalizadas do que antes. Além da modernidade, devo argumentar, podemos perceber os contornos de uma ordem nova e diferente, que é "pós-moderna"; mas isto é bem diferente do que é atualmente chamado por muitos de "pós-modernidade". (GIDDENS, 1991, p.09).
\end{abstract}

Nesta direção, também é possível perceber que há uma convergência nas tentativas de se estabelecer o entendimento do contexto contemporâneo. Nota-se a confirmação da existência de um tempo no qual se predomina a dinamicidade dos movimentos e episódios culturais, sociais e econômicos, o que, dentre outras coisas, surge por influência das alterações nos modos de pensar e das concepções sobre a legitimação dos saberes, impactada profundamente pelo advento das tecnologias da informação e comunicação. Para alguns estudiosos pós-estruturalistas, o momento é marcado pela perda das incertezas, bem como pela dinamicidade da troca de informações e pela falência na crença do estabelecimento dos relatos científicos.

O pós-moderno pode ser definido por Lyotard (2000, p. 12) como "a incredulidade em relação às metanarrativas. Esta é, sem dúvida, um efeito do progresso das ciências, mas este progresso pressupõe-na". Nessa direção, a experiência da pós-modernidade transcorreria da perda das crenças em visões totalizantes da história, proporcionando um clima de desconfiança em relação aos discursos que proponham consensos universais. 


\title{
5. O DESIGN E O PÓS-INDUSTRIALISMO
}

As transformações ocorridas a partir da segunda metade do século XX podem também ser analisadas a partir de alguns dos pontos de vista específicos. Dentre outros é possível considerar o advento de tais mudanças a partir da ótica do chamado pós-industrialismo, conforme Bell (1976), período no qual se observa o nascimento das chamadas tecnologias da informação e comunicação, dentre elas a informática.

Nos dizeres de Bell,

\begin{abstract}
a sociedade pré-industrial é do tipo agrário, estruturada em moldes tradicionais, onde o poder está em regra associado à propriedade da terra. $\mathrm{A}$ sociedade industrial apoia-se na produção de bens industriais e o poder nela instituído pertence aos capitalistas. A sociedade pós-industrial tem por base os serviços e a fonte do poder nela existente radica na informação. Esta sociedade pauta-se, pois, pela ascensão dos serviços, que se tornam hegemônicos e, inversamente, pelo declínio das atividades industriais. (BELL, 1976, p. 148)
\end{abstract}

Na sociedade pré-industrial, a vida era condicionada por elementos naturais e a força de trabalho comprometida com a agricultura, com a mineração e com a pesca. Na sociedade industrial, a atividade predominante era a produção de mercadorias. Já a sociedade pós-industrial é baseada em serviços, e o que prevalece é a informação.

Em especial é possível considerar que a partir da segunda metade do século XX foi notável o surgimento de uma série de mudanças tecnológicas que impactaram diretamente na sociedade e contribuíram para o advento de um novo tipo de sociedade. Cita-se, por exemplo, a teoria do pós-industrialismo caracterizado pelo desenvolvimento das tecnologias da informação e comunicação.

Nesse sentido, tem-se o aparecimento de mudanças significativas e o surgimento de inovações tecnológicas que impactaram diretamente nas relações sociais, bem como alteraram os modos de produção, trazendo mudanças na esfera do trabalho e também rupturas no âmbito de diversos campos do conhecimento. Podese considerar tal período como um marco que possibilitou novos modos de pensar o processo produtivo industrial, bem como as mudanças que nasceram em consequência das possibilidades de troca e armazenamento de informações que promoveram diversas reflexões sobre o conceito de saber, o conceito de ciência e o conceito de trabalho.

As diversas mudanças atuais são transformações que foram influenciadas pelo surgimento das tecnologias da informação e comunicação e de fenômenos que amplificaram as relações entre os indivíduos dispersos geograficamente, possibilitando um rearranjo sociocultural e econômico no sentido de se estruturar uma rede para simplificar as várias trocas, sejam elas de informações, de culturas e/ou de mercadorias. Observa-se nesse sentido que o nascimento do fenômeno da globalização modificou as interações entre as pessoas em escala global, impactando localmente em seu modo de pensar e agir. 
Para Anthony Giddens,

\begin{abstract}
a globalização pode assim ser definida como a intensificação das relações sociais em escala mundial, que ligam localidades distantes de tal maneira que acontecimentos locais são modelados por eventos ocorrendo a muitas milhas de distância e vice-versa. Este é um processo dialético porque tais acontecimentos locais podem se deslocar numa direção inversa às relações muito distanciadas que os modelam. A transformação local é tanto uma parte da globalização quanto a extensão lateral das conexões sociais através do tempo e do espaço. Assim, quem quer que estude as cidades hoje em dia, em qualquer parte do mundo, está ciente de que o que ocorre numa vizinhança local tende a ser influenciado por fatores - tais como dinheiro mundial e mercados de bens - operando a uma distância indefinida da vizinhança em questão. (GIDDENS, 1991, p. 60).
\end{abstract}

Tal intensificação das relações na sociedade propiciou também um novo arranjo nos hábitos sociais, no qual a sociedade passou a ter uma simplificação nas práticas de compra pelo fato da globalização impulsionar uma ampliação na concorrência entre os mercados já não mais apenas locais, porém globais. Além disso, determinados fenômenos, como o crescimento e o amadurecimento da informática e da telemática, somada ao advento da globalização, começaram a possibilitar um acesso mais fácil a compras em regiões onde anteriormente era mais complexo o contato. Embora se considere que a globalização promova uma aproximação entre as nações, é preciso notar também seus impactos negativos, pois, em contrapartida, tal fenômeno também é responsável pelo aumento da exclusão de comunidades menos favorecidas economicamente em função de diversos aspectos, como a carência de valores a serem oferecidos na rede global, por exemplo.

Existe uma nova ordem econômica e social cujo centro das transformações está na revolução tecnológica concentrada nas tecnologias da informação e comunicação. Paralelamente, as mudanças sociais, a nova consciência ambiental, a crise de legitimidade dos sistemas políticos e a fragmentação dos movimentos sociais caracterizam um cenário de transformações. Para Castells (1999, p. 23), "nesse mundo de mudanças confusas e incontroladas, as pessoas tendem a reagrupar-se em torno de identidades primárias: religiosas, étnicas, territoriais, nacionais".

Dessa forma, uma compreensão que pode ser estabelecida para o entendimento do momento atual está na apreensão deste período pelo nascimento de novos hábitos que impactaram e caracterizaram profundamente a sociedade contemporânea, sendo possível constatar o surgimento de uma sociedade que valoriza as práticas de consumo, práticas essas capazes de se estabelecerem um jogo de afirmação e confirmação de identidades individuais e de destaque das condições de status. Neste caso específico, tem-se o entendimento de uma dinâmica social em que o objeto é a prática da compra de objetos, vista como uma ação que favorece o processo de evidenciação de determinados indivíduos entre outros, numa lógica em que, quem tem a possibilidade de compra em grandes quantidades, se destaca entre os demais.

Nesse sentido, é relevante observar que o design precisa assumir um papel capaz de contribuir na caracterização de aspectos sociais nos quais se estabeleça um 
determinado arranjo que compreenda os hábitos de consumo atuais, mas que considere uma reflexão sobre os valores locais e favoreça a construção de uma sociedade ambientalmente sustentável. Uma sociedade que considere propostas que valorizem aspectos ecológicos e que possa contribuir para a diminuição de desigualdades e atenuar gradativamente a exclusão de culturas menos favorecidas economicamente.

As valiosas contribuições de Burdek (2006), Cardoso (2004), Maldonado (1999) e Schneider (2010) no campo do Design já sinalizam a importância de se considerar os variados aspectos relacionados aos fenômenos contemporâneos que impactam diretamente as práticas projetuais e substancialmente o conceito de Design. $O$ presente artigo corrobora com as postulações destes autores, porém preconiza a importância de se ampliar as reflexões relacionadas a tais transformações de modo teórico e prático revigorando os modos de conceber e praticar o Design na contemporaneidade. Notavelmente se percebe que a atividade de design desde sua origem, esteve conectada e articulada em determinado contexto histórico com suas particularidades, seus limites e dependente da demanda tecnológica disponível. Também se reconhece que o impacto gerado pela prática do Design tornou-se o próprio reflexo da sociedade em que esteve inserido. Modificando, provocando, estimulando, desafiando e adequando as produções humanas e suas implicações coletivas e particulares.

\section{CONCLUSÃO}

Ao analisar criticamente o percurso histórico do design, observa-se que, em geral, ocorre uma dedicação para se discutir seus principais precursores e também evidenciar uma relação com as principais escolas que impulsionaram sua caracterização ao longo dos anos. Porém, ainda há uma carência em discussões sobre as práticas do design em meio às mudanças proporcionadas pelo advento de fenômenos que marcam a sociedade atual e a cultura pós-moderna. Faz-se necessário revisitar as várias influências que o design sofreu ao longo dos anos, promovendo uma análise no âmbito das rupturas que atualmente impactam diretamente o design, propiciando um envolvimento mais direto no âmbito da cultura, da arte, das relações sociais e ambientais. Percebe-se que é necessário realizar uma constante análise crítica e profunda sobre o seu papel diante de uma sociedade cada vez mais dinâmica, plural e complexa.

Torna-se fundamental reconhecer o conceito de design, o seu significado para a sociedade e as dimensões envolvidas no âmbito da cultura pós-moderna. De tal forma, torna-se possível associar as práticas do design em seu respectivo contexto mutante e dinâmico, e não apenas constituir esforços em delimitar seu campo de atuação. É necessário ir além da mera distinção do que seja ou não design, para que, dessa maneira, seja possível uma ampliação de horizontes. Nessa direção, é possível construir indagações sobre o design e a contemporaneidade.

Sem isolar uma análise reflexiva do conceito do design, é possível estabelecer uma reflexão dialética sobre quais contribuições do design na caracterização da cultura pós-moderna, ou mesmo analisar quais os aspectos culturais do período pós-moderno que diretamente influenciaram o design na sociedade atual. 


\section{AGRADECIMENTOS}

Agradeço à Fundação de Amparo à Pesquisa do Estado de Minas Gerais (FAPEMIG) pelo apoio financeiro.

\section{REFERÊNCIAS}

BAUDRILLARD, Jean. A Sociedade de consumo. Lisboa/Portugal: Edições 70, 2005.

BAUMAN, Zygmunt. Modernidade Líquida. Rio de Janeiro: Jorge Zahar Editor, 2000.

BAUMAN, Zygmunt. O mal-estar da pós-modernidade. Rio de Janeiro: Jorge Zahar Editor, 1999.

BELL, Daniel. 0 advento da sociedade pós-industrial: uma tentativa de previsão social. Tradução de Heloysa de Lima Dantas. São Paulo: Editora Cultrix, 1973.

BÜRDEK, Bernhard E. História, teoria e prática do design de produtos. São Paulo: Edgard Blucher, 2006.

CARDOSO, Rafael. Uma introdução à história do design. São Paulo: Edgard Blucher, 2004.

CASTELLS, Manuel. A sociedade em rede. São Paulo: Paz e Terra, 1999.

GIDDENS, Anthony. As consequências da modernidade. São Paulo: Editora UNESP, 1991.

LYOTARD, Jean-François. A condição pós-moderna. 6. ed. Rio de Janeiro: José Olympio, 2000.

MALDONADO, Tomás. Design Industrial. Lisboa/Portugal: Edições 70, 1999.

SCHNEIDER, Beat. Design: uma introdução. São Paulo: Edgar Blucher, 2010. 